Research Article

\title{
The Association between Gly460Trp-Polymorphism of Alpha-Adducin 1 Gene (ADD1) and Arterial Hypertension Development in Ukrainian Population
}

\author{
Svitlana Yermolenko (D), ${ }^{1}$ Yaroslav Chumachenko $\left(\mathbb{D}^{2},{ }^{2}\right.$ Viktor Orlovskyi (iD, ${ }^{1}$ \\ Irina Moiseyenko $\left(\mathbb{C}^{1}{ }^{1}\right.$ and Oleksandr Orlovskyi $\mathbb{C}^{1}$ \\ ${ }^{1}$ Department of Family Medicine, Medical Institute of the Sumy State University, Sumy 40035, Ukraine \\ ${ }^{2}$ Scientific Laboratory of Molecular Genetic Research, Medical Institute of the Sumy State University, Sumy 40035, Ukraine \\ Correspondence should be addressed to Yaroslav Chumachenko; yaroslavus.dm@gmail.com
}

Received 8 February 2021; Accepted 22 April 2021; Published 4 May 2021

Academic Editor: Thereza Maria Magalhães Moreira

Copyright (C) 2021 Svitlana Yermolenko et al. This is an open access article distributed under the Creative Commons Attribution License, which permits unrestricted use, distribution, and reproduction in any medium, provided the original work is properly cited.

\begin{abstract}
Arterial hypertension $(\mathrm{AH})$ belongs to the diseases with genetic predisposition that determines the necessity of research on the genetic component's influence on this disease development. It is suggested that one of the salt-sensitive arterial hypertension potential markers may be the alpha-adducin gene because its protein product is involved in the ion transport regulation in the renal epithelium. Thus, the aim of the study was to investigate the association between ADD1 Gly460Trp-polymorphism and the $\mathrm{AH}$ development risk among patients with different risk factors in the Ukrainian population. The study included 232 Ukrainians: 120 patients with diagnosed arterial hypertension and 112 practically healthy individuals. Polymerase chain reaction-restriction fragment length polymorphism (PCR-RFLP) analysis was used for ADD1 Gly460Trp-polymorphism genotyping. The ADD1 Gly460Trp-polymorphic locus is an important predictor of arterial hypertension development in the Ukrainian population, but other nongenetic factors should be considered in further studies.
\end{abstract}

\section{Introduction}

Arterial hypertension $(\mathrm{AH})$ is the leading preventable risk factor of cardiovascular diseases (CVDs). Its prevalence is about $30-45 \%$ of the total population and increases with age. High arterial blood pressure (BP) is known to provoke and accelerate the development of atherosclerosis, which significantly increases the incidence of coronary heart disease, stroke, heart, and kidney failure [1].

Arterial hypertension is a disease with a genetic predisposition, whose development depends on the complex interaction of environmental factors and genetic markers that influence the individual risk of disease occurrence, its course, and the complications formation. There are nonmodifiable (sex, age, and burdened heredity) and modifiable (overweight and obesity, smoking, alcohol consumption, high-salt intake, stress, etc.) AH risk factors [2].
Genetic factors play an important role in AH development. Therefore, there are a lot of studies that focused on the $\mathrm{AH}$ risk genes detection, whose expression products can directly or indirectly affect the $\mathrm{AH}$ occurrence and the clinical manifestations of pathogenetically related CVD [3-5]. There is a separate area of research devoted to the study of the gene single nucleotide polymorphisms (SNP) role, whose products are important in the $\mathrm{AH}$ pathogenesis $[4,6]$.

Present genetic epidemiological studies suggest that the adducin gene may be an important potential marker gene for $\mathrm{AH}$, especially for salt-sensitive [7]. Today, there are 3 major loci in the adducin family genes that correlate with the $\mathrm{AH}$ development-Gly460Trp ADD1, C1797T ADD2, and A386G $A D D 3[8,9]$.

A number of population studies revealed an association between the Gly460Trp $\mathrm{T}$ allele (ADD1 gene) and $\mathrm{AH}$ 
development [10-18]; however, in others, this link is absent [19-22]. It should be noted that data on the association between ADD1 Gly460Trp-polymorphism and the AH occurrence remain controversial and demonstrate the interpopulation differences in the association of gene polymorphic variants with the risk of $\mathrm{AH}$ development. Many studies have shown that differences in genotype distribution can significantly fluctuate in various ethnic groups [10-22]. Therefore, the association between these or other polymorphic markers and the $\mathrm{AH}$ development is contradictory in different populations, making research for each ethnic and population group significant $[8,22-24]$.

The purpose of this work is to investigate the association between Gly460Trp-polymorphism of the alpha-adducin 1 $(A D D 1)$ gene and the $\mathrm{AH}$ development risk among patients with different risk factors in the Ukrainian population.

\section{Materials and Methods}

2.1. Study Population. The present hospital-based casecontrol study enrolled 232 Ukrainians that had been under observation in Sumy Regional Hospital and 1th Sumy Clinical Hospital from 2018 to 2019. All participants were selected from the medical records and divided into case groups with diagnosed $\mathrm{AH}$ and a control group of relatively healthy controls without $\mathrm{AH}$. The first group involved 120 patients (46 males and 74 females; mean age $( \pm S D)$ $53.33 \pm 14.55)$ with a verified diagnosis of $\mathrm{AH}$ II clinical stage. Verification of diagnosis and determination of $\mathrm{AH}$ stage and grade were estimated according to WHO criteria (1999) [25] and European Society of Cardiology (2007) [26]. The control group included 112 practically healthy normotensive individuals (73 males and 39 females; mean age $57.89 \pm 10.05)$. Exclusion criteria from the study group were the symptomatic $\mathrm{AH}$, endocrine obesity, pregnancy and lactation, acute infectious diseases, exacerbation of chronic infectious diseases, neoplasms, mental disorders and nervous system diseases, systemic connective tissue diseases, acute disorders of cerebral circulation (up to 3 months), and the patient's refusal to participate in the research.

At the next stage, patients with hypertension were divided into two subgroups-with a salt-sensitive and saltresistant course of the disease (Table 1). Elijovich technique was used to determine the type of salt sensitivity. The essence of this method is to stick to a high-salt diet with a further restriction on salt intake. Sticking to a diet was evaluated by daily urinary sodium excretion during high-salt and low-salt diets using electrolyte analyzer "Ionometer3" (Fresenius Medical Care AG and Co. KGaA, Germany) for ion-selective urine potentiometry. There was a characteristic of dependence on the salt diet: patients were referred to salt-sensitive if after switching from high-salt to low-salt diets, systolic blood pressure (SBP) decreased by more than $10 \mathrm{mmHg}$; to salt-resistant if after changing diets, SBP did not decrease by more than $5 \mathrm{mmHg}$; and individuals with a paradoxical reaction to the change in salt load and a decrease in SBP during the switching to a low-salt diet [27].

Anthropometric data (age, sex, BMI, and smoking habit) was recorded at the time of selection to the study. BP was
TABLE 1: Clinical characteristics of the patients with various $\mathrm{AH}$ forms.

\begin{tabular}{lccc}
\hline Parameter & $\begin{array}{c}\text { SS } \\
(n=62)\end{array}$ & $\begin{array}{c}\text { SR } \\
(n=58)\end{array}$ & $P$ \\
\hline Age, years & $51.44 \pm 14.91$ & $55.36 \pm 13.99$ & 0.14 \\
Sex, female/male & $16 / 46$ & $30 / 28$ & 0.004 \\
BMI, kg/m ${ }^{2}$ & $29.72 \pm 4.72$ & $25.17 \pm 3.33$ & $<0.001$ \\
Smokers, $n$ (\%) & $10(16.1)$ & $11(19)$ & 0.683 \\
Sodium, urine (I phase) & $20.11 \pm 4.85$ & $19.78 \pm 4.54$ & 0.696 \\
Sodium, urine (II phase) & $203.1 \pm 12.17$ & $205.0 \pm 11.88$ & 0.388 \\
Glucose, mmol/L & $4.55 \pm 0.63$ & $4.57 \pm 0.67$ & 0.86 \\
Total cholesterol, mmol/L & $4.48 \pm 1.25$ & $4.36 \pm 1.06$ & 0.583 \\
Triglyceride, mmol/L & $1.54 \pm 0.92$ & $1.38 \pm 0.79$ & 0.3 \\
HDL cholesterol, mmol/L & $1.08 \pm 0.17$ & $1.07 \pm 0.13$ & 0.689 \\
LDL cholesterol, mmol/L & $2.7 \pm 1.04$ & $2.67 \pm 0.96$ & 0.861 \\
VLDL cholesterol, mmol/L & $0.65 \pm 0.31$ & $0.63 \pm 0.35$ & 0.859 \\
AIP & $3.33 \pm 1.6$ & $3.18 \pm 1.33$ & 0.583 \\
\hline
\end{tabular}

$n$ : number of cases; AH: arterial hypertension; SS: salt-sensitive; SR: saltresistant; BMI: body mass index; HDL: high-density lipoprotein; LDL: lowdensity lipoprotein; VLDL: very low-density lipoprotein; AIP: atherogenic index of plasma.

measured on three occasions, and the mean of the last two was used in the analysis. Fasting glucose and lipid profile parameters (total cholesterol, triglyceride, high, low, and very low-density lipoprotein cholesterol, and atherogenic index of plasma) were recorded at the time of diagnosis. Daily urinary sodium excretion was performed for patients with diagnosed $\mathrm{AH}$ to determine the type of salt sensitivity.

The study protocol was implemented in accordance with the Declaration of Helsinki and was approved by the Ethics Committee of the Medical Institute of Sumy State University. Patients were introduced to the study protocol and they gave a voluntary informed written consent.

2.2. Genotyping. ADD1 Gly460Trp-polymorphism determination was performed using the polymerase chain reaction-restriction fragment length polymorphism analysis (PCR-RFLP). DNA was isolated from $50 \mu \mathrm{L}$ of whole venous blood according to the manufacturer's standard protocol using «NeoPrep ${ }^{100}$ DNA_Blood» (Neogene). A reaction mixture for the amplification (total volume $25 \mu \mathrm{L}$ ) was composed of $5 \mu \mathrm{L}$ FastDigest Green Buffer (10X) (Thermo Scientific $^{\mathrm{TM}}$, USA), $0.5 \mu \mathrm{L}$ dNTP Mix (containing $10 \mathrm{mM}$ of each deoxyribonucleotide) (Thermo Scientific ${ }^{\mathrm{TM}}$, USA), 0.75 U DreamTaq DNA Polymerase $(5 \mathrm{U} / \mu \mathrm{L})$ (Thermo Scientific $^{\mathrm{TM}}$, USA), $0.1 \mu$ of each primer, $2 \mu \mathrm{L}$ DNA, and deionized water to the total volume. PCR was carried out using the Thermocycler GeneAmp PCR system 2700 (Thermo Fisher Scientific, USA). The primer nucleotide structure and PCR stages are shown in Table 2.

The reaction mixture (total volume $2 \mu \mathrm{L}$ ) for restriction included $0.8 \mu \mathrm{L}$ CutSmart Buffer (New England BioLabs), $0.2 \mu \mathrm{L}$ Sau $96 \mathrm{I}$ (New England BioLabs), and deionized water to the total volume. Samples were incubated in a thermostat at $37^{\circ} \mathrm{C}$ for $20 \mathrm{~h}$.

Horizontal electrophoresis $(10 \mathrm{~V} / \mathrm{cm})$ in $2.5 \%$ agarose gel with the addition of a bromide ethidium solution $(10 \mathrm{mg} / \mathrm{ml})$ was used for genotyping. Discrimination of genotypes was 
TAble 2: Primer nucleotide sequence and PCR conditions.

\begin{tabular}{|c|c|c|c|c|c|}
\hline \multirow{2}{*}{ Primer nucleotide sequence } & \multicolumn{3}{|c|}{ PCR conditions ( $n=40$ cycles $)$} & \multirow{2}{*}{ PCR amplicon size } & \multirow{2}{*}{ Restriction fragments } \\
\hline & $\mathrm{D}$ & $\mathrm{H}$ & $\mathrm{E}$ & & \\
\hline Fwd: 5 'GACCCTAGGGCTACAGAACTG3' & \multirow[b]{2}{*}{$94^{\circ} \mathrm{C}(30 \mathrm{~s})$} & \multirow[b]{2}{*}{$63^{\circ} \mathrm{C}(30 \mathrm{~s})$} & \multirow[b]{2}{*}{$72^{\circ} \mathrm{C}(30 \mathrm{~s})$} & \multirow[b]{2}{*}{252} & GG $225 ; 27$ \\
\hline Rev: 5`TCGACTTGGGACTGCTTCCATTCGGCC3` & & & & & $\begin{array}{c}\text { GT } 252 ; 225 ; 27 \\
\text { TT } 252\end{array}$ \\
\hline
\end{tabular}

D: denaturation; H: hybridization; E: elongation; Fwd: forward primer; Rev: reverse primer.

carried out using a transilluminator ("Biocom", Russia). The presence of the G allele at the 66124th position of the ADD1 gene (NG_012037.1) led to the splitting of the amplicon (252 bp) by Sau96I-restrictase into two parts of $225 \mathrm{bp}$ and $27 \mathrm{bp}$. The presence of $\mathrm{T}$ allele resulted in preventing the restriction, and the original fragment $(252 \mathrm{bp})$ was preserved (Figure 1).

2.3. Statistical Analysis. The Statistical Package for Social Science software (SPSS, version 25.0, Chicago, IL, USA) was applied for statistical analysis of the obtained results. Continuous variables were presented as the mean $\pm S D$, and categorical variables as absolute and percentage values. Chisquare $\left(\chi^{2}\right)$ test was used for comparing the frequency of alleles, genotypes, and other categorical variables. A twotailed Student's $t$-test was used to compare the mean values (with preliminary verification of the data distribution for normality according to the Shapiro-Wilk test). The correspondence of the allele frequency distribution to HardyWeinberg equilibrium was carried out using the Calculator of Hardy-Weinberg equilibrium (https://wpcalc.com/en/ equilibrium-hardy-weinberg). The binary logistic regression was used in the framework of recessive, dominant, overdominant, and additive inheritance models to analyze the association between the ADD1 rs4961-polymorphic variant and $\mathrm{AH}$ development. Adjustments for age, sex, body mass index (BMI), smoking habit, $\mathrm{AH}$ grade, and the $\mathrm{AH}$ presence in family history were applied to improve the reliability of the obtained results. «Sex» and «BMI» covariates were explored as effect modifiers by adding the «model of inheritance*sex» and «model of inheritance*BMI» independent variables to the logistic regression, respectively. All $P$ values are two-tailed; a value of $P<0.05$ was accepted as significant.

\section{Results}

Statistically significant differences were revealed between salt-sensitive and salt-resistant patients in sex $(P=0.004)$ and BMI $(P<0.001)$. On the other hand, the comparison subgroups did not significantly differ in age, number of smokers, and laboratory test results $(P>0.05)$ (Table 1$)$.

The frequency of $A D D 1$ Gly460Trp genotypes and alleles and correspondence of the distribution of the major and minor alleles to Hardy-Weinberg equilibrium are summarized in Table 3. Both the control and main groups did not significantly deviate from Hardy-Weinberg equilibrium expectations $\left(P_{\mathrm{HWE}}=0.452\right.$ and $P_{\mathrm{HWE}}=0.494$, respectively).

The distribution of ADD1 Gly460Trp genotypes and alleles analysis indicated that among $120 \mathrm{AH}$ patients, 91

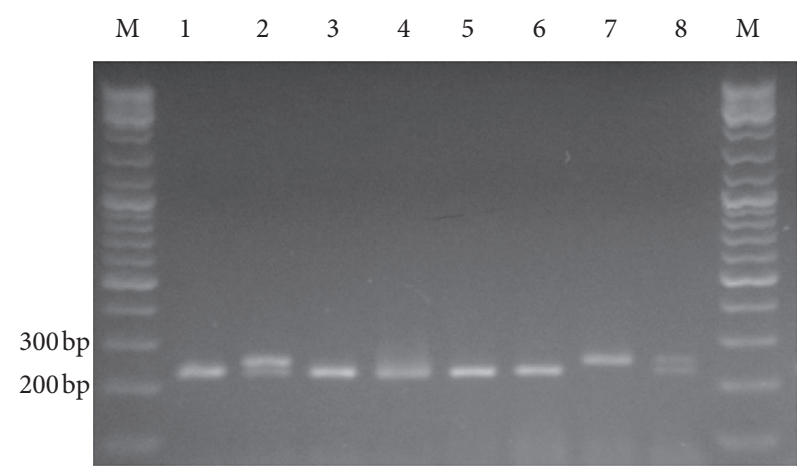

FIgURE 1: Results of the ADD1 rs4961-polymorphism genotyping. M: molecular marker; bp: base pairs; 1, 3, 4, 5, 6: GG genotype; 2, 8: GT genotype; 7: TT genotype.

TABle 3: Distribution of the ADD1 rs4961-polymorphism alleles and genotypes in comparison groups.

\begin{tabular}{|c|c|c|c|c|}
\hline & \multicolumn{2}{|c|}{$\begin{array}{c}\mathrm{AH} \\
(n=120)\end{array}$} & \multicolumn{2}{|c|}{$\begin{array}{l}\text { Control } \\
(n=112)\end{array}$} \\
\hline & $\mathrm{n}$ & $\%$ & $\mathrm{n}$ & $\%$ \\
\hline & \multicolumn{4}{|c|}{ Genotypes } \\
\hline GG & 91 & 75.8 & 98 & 87.5 \\
\hline GT & 26 & 21.7 & 13 & 11.6 \\
\hline TT & 3 & 2.5 & 1 & 0.9 \\
\hline \multirow[t]{2}{*}{$\mathrm{P}$} & \multicolumn{4}{|c|}{0.07} \\
\hline & \multicolumn{4}{|c|}{ Alleles } \\
\hline G & 224 & 87.5 & 209 & 93.3 \\
\hline $\mathrm{T}$ & 32 & 12.5 & 15 & 6.7 \\
\hline $\mathrm{P}$ & \multicolumn{4}{|c|}{0.033} \\
\hline$P_{\text {HWE }}$ & & & & \\
\hline
\end{tabular}

AH: arterial hypertension; $n$ : number of cases; $P_{H W E}: P$ value of Hardy-Weinberg equilibrium.

(75.8\%) had the G allele in homozygosis, 3 (2.5 \%) had the T allele in homozygosis, and $26(21.7 \%)$ were heterozygous. The frequency of AH patients' G allele was 0.87 , and $T$ was 0.13. And, 98 (87.5 \%) had GG genotype, 13 (11.6\%) had GT genotype, and $1(0.9 \%)$ had TT genotype among practically healthy individuals. The $G$ and $T$ frequencies were 0.93 and 0.07 , respectively. Chi-square $\left(\chi^{2}\right)$ test did not reveal a distinction in the distribution of ADD1 Gly460Trp genotypes and alleles in control and $\mathrm{AH}$ patients $(P=0.07)$; instead, statistically significant differences in the allele frequency were established $(P=0.033)$.

A binary logistic regression was used to estimate the $\mathrm{AH}$ occurrence risk depending on the ADD1 Gly460Trp genotypes (Table 4). An AH development risk for minor allele carriers $(\mathrm{GT}+\mathrm{TT})$ is higher $\left(\mathrm{OR}_{\mathrm{c}}=2.231 ; 95 \%\right.$ 
TABLE 4: Analysis of the ADD1 rs4961-polymorphism association with arterial hypertension occurrence.

\begin{tabular}{lcccc}
\hline Model of inheritance & $P_{c}$ & $\mathrm{OR}_{\mathrm{c}}(95 \% \mathrm{CI})$ & $P_{a}{ }^{1}$ & $\mathrm{OR}_{\mathrm{a}}(95 \% \mathrm{CI})$ \\
\hline Dominant & 0.024 & $2.231(1.109-4.487)$ & $0.046(0.261)$ & $2.138(1.014-4.509)$ \\
Recessive & 0.368 & $2.846(0.292-27.711)$ & $0.475(0.541)$ & $2.32(0.23-23.413)$ \\
Overdominant $^{*}$ Additive $^{\mathrm{a}}$ & 0.043 & $2.106(1.022-4.341)$ & $0.072(0.352)$ & $2.023(0.939-4.359)$ \\
& 0.038 & $2.154(1.044-4.444)$ & $0.061(0.299)$ & $2.087(0.966-4.51)$ \\
\hline
\end{tabular}

$P_{c}$ : crude $P$ value; $\mathrm{OR}_{c}$ : crude odds ratio; $P_{a}: P$ value adjusted for age, $\mathrm{BMI}$, and smoking habit; $\mathrm{OR}_{\mathrm{a}}$ : odds ratio adjusted for age, $\mathrm{BMI}$, and smoking habit; $95 \%$ CI: 95\% confidence interval. a: upper row: comparison between GT and TT genotypes; lower row: comparison between TT and GG genotypes. 1: $P$ value adjusted for sex is shown in parentheses.

$\mathrm{CI}=1.109-4.487)$ than that for a major allele in homozygosis $(\mathrm{GG})\left(\mathrm{P}_{\mathrm{c}}=0.024\right)$. Also, GT genotype has higher $\mathrm{AH}$ development risk than GG genotype under overdominant and additive models of inheritance $\left(\mathrm{OR}_{\mathrm{c}}=2.106 ; 95 \%\right.$ $\mathrm{CI}=1.022-4.341 ; \mathrm{P}_{\mathrm{c}}=0.043$ for overdominant; $\mathrm{OR}_{\mathrm{c}}=2.154$; $95 \% \mathrm{CI}=1.044-4.444 ; \quad \mathrm{P}_{\mathrm{c}}=0.038$ for additive). After adjusting for the covariates (age, BMI, and smoking habit), a significant association remained under the dominant model $\left(\mathrm{OR}_{\mathrm{a}}=2.138 ; 95 \% \mathrm{CI}=1.014-4.509 ; \mathrm{P}_{\mathrm{a}}=0.046\right)$. However, after adjusting for the sex, the dominant model lost its statistical significance $\left(P_{a}=0.261\right)$.

The next stage was to study the Gly460Trp-polymorphism genotypes distribution, considering some $\mathrm{AH}$ risk factors.

Statistically significant differences were found in the distribution of genotypes $(P=0.002)$ and alleles $(P<0.001)$ among individuals of different sexes (Table 5). Thus, 48 (64.8\%) subjects with GG genotype, 23 (31.1\%) with GT genotype, and $3(4.1 \%)$ with TT genotype were among females with $\mathrm{AH}$; minor allele frequency was 0.19 . Also, there were 43 (93.5 \%) males with GG genotype and $3(6.5 \%)$ with GT genotype; minor allele frequency was 0.03 (there were no males with TT genotype).

AH patients were divided into groups with normal and elevated BMI to reveal significant differences in the genotype distribution in individuals with different BMIs $(P=0.008)$ (Table 5). Thus, 40 (64.5\%) subjects with GG genotype, 19 (30.7\%) with GT genotype, and 3 (4.8\%) with TT genotype were among $\mathrm{AH}$ patients with $\mathrm{BMI} \geq 25 \mathrm{~kg} / \mathrm{m}^{2}$. AH patients with BMI $<25 \mathrm{~kg} / \mathrm{m}^{2}$ had the following distribution of GG, GT, and TT genotypes: 51 (87.9\%), 7 (12.1\%), and 0 (0\%), respectively. The minor allele frequency in the first group was 0.2 and 0.06 in the second group which had statistically significant differences in its distribution $(P=0.001)$.

The distribution of G/G, G/T, and T/T genotypes in saltsensitive patients significantly differed from salt-resistant patients $(P=0.022)$ (Table 5). The genotype distribution was 41 (66.2\%), 18 (29\%), and 3 (4.8\%) for salt-sensitive patients and $50(86.2 \%), 8(13.8 \%)$, and $0(0 \%)$ for salt-resistant patients, respectively. The minor allele frequency in the first group was 0.19 and 0.07 in the second group which had statistically significant differences in its distribution $(P=0.005)$.

There were no statistically significant differences in $A D D 1$ Gly460Trp genotypes $(P=0.069)$ and minor allele $(P=0.424)$ distributions among subjects with smoking habits.
TABLE 5: The ADD1 rs4961-polymorphism allelic variants frequency in subjects with different $\mathrm{AH}$ risk factors.

\begin{tabular}{|c|c|c|c|c|c|}
\hline \multirow[b]{2}{*}{ Risk factors } & \multicolumn{5}{|c|}{ Genotypes } \\
\hline & $\begin{array}{c}\mathrm{G} / \mathrm{G}, n \\
(\%)\end{array}$ & $\begin{array}{c}\mathrm{G} / \mathrm{T}, n \\
(\%)\end{array}$ & $\begin{array}{c}\mathrm{T} / \mathrm{T}, n \\
(\%)\end{array}$ & $\mathrm{G}, n(\%)$ & $\mathrm{T}, n(\%)$ \\
\hline Males & $43(93.5)$ & $3(6.5)$ & $0(0)$ & $\begin{array}{c}89 \\
(96.7)\end{array}$ & $3(3.3)$ \\
\hline \multirow[t]{2}{*}{ Females } & $48(64.8)$ & $23(31.1)$ & $3(4.1)$ & $\begin{array}{c}119 \\
(80.4)\end{array}$ & $29(19.6)$ \\
\hline & \multicolumn{3}{|c|}{$\mathrm{P}=0.002$} & \multicolumn{2}{|c|}{$\mathrm{P}<0.001$} \\
\hline $\mathrm{BMI}<25$ & $51(87.9)$ & $7(12.1)$ & $0(0)$ & $109(94)$ & $7(6)$ \\
\hline \multirow[t]{2}{*}{$\mathrm{BMI} \geq 25$} & $40(64.5)$ & $19(30.7)$ & $3(4.8)$ & $\begin{array}{c}99 \\
(79.8)\end{array}$ & $25(20.2)$ \\
\hline & \multicolumn{3}{|c|}{$\mathrm{P}=0.008$} & \multicolumn{2}{|c|}{$\mathrm{P}=0.001$} \\
\hline Nonsmoker & $74(74.8)$ & $22(22.2)$ & $3(3)$ & $\begin{array}{c}170 \\
(85.9)\end{array}$ & $28(14.1)$ \\
\hline \multirow[t]{2}{*}{ Smoker } & $17(81)$ & $4(19)$ & $0(0)$ & $\begin{array}{c}38 \\
(90.5)\end{array}$ & $4(9.5)$ \\
\hline & \multicolumn{3}{|c|}{$\mathrm{P}=0.669$} & \multicolumn{2}{|c|}{$\mathrm{P}=0.424$} \\
\hline \multirow{3}{*}{$\begin{array}{l}\text { Salt- } \\
\text { resistant } \\
\text { Salt- } \\
\text { sensitive }\end{array}$} & $50(86.2)$ & $8(13.8)$ & $0(0)$ & $\begin{array}{c}108 \\
(93.1)\end{array}$ & $8(6.9)$ \\
\hline & $41(66.2)$ & $18(29)$ & $3(4.8)$ & $\begin{array}{c}100 \\
(80.6)\end{array}$ & $24(19.4)$ \\
\hline & \multicolumn{3}{|c|}{$\mathrm{P}=0.022$} & \multicolumn{2}{|c|}{$\mathrm{P}=0.005$} \\
\hline
\end{tabular}

$n$ : number of cases; BMI: body mass index.

A binary logistic regression was used to estimate the $\mathrm{AH}$ occurrence risk among patients of different sexes depending on the ADD1 Gly460Trp genotypes (Table 6). There was no statistically significant AH development risk in different genotypes under each inheritance model $\left(P_{c}>0.05\right)$. However, after adjusting for covariates (age, BMI, and smoking habit), a significant link was revealed under the dominant model in females $\left(\mathrm{OR}_{\mathrm{a}}=2.787 ; 95 \% \mathrm{CI}=1.022-7.6\right.$; $\mathrm{P}_{\mathrm{a}}=0.045$ ). Thus, sex can be defined as a risk modifier for AH development $\left(P_{\mathrm{a}}\right.$ int $\left.=0.049\right)$. It confirms the view that the $\mathrm{AH}$ development risk is higher in females with the $\mathrm{T}$ allele presence.

After regression analysis, the risk of $\mathrm{AH}$ development in patients with different $A D D 1$ Gly460Trp genotypes was determined depending on BMI (Table 7). A significant association between ADD1 rs4961-polymorphic variant and $\mathrm{AH}$ was revealed for the patients with $\mathrm{BMI} \geq 25 \mathrm{~kg} / \mathrm{m}^{2}$ under all models of inheritance. The minor $\mathrm{T}$ allele $(\mathrm{GT}+\mathrm{TT})$ carriers were found to have a higher $\mathrm{AH}$ development risk than $G$ allele $(\mathrm{GG})$ carriers $\left(\mathrm{P}_{\mathrm{c}}=0.001\right)$ under the dominant model $\left(\mathrm{OR}_{\mathrm{c}}=4.408 ; 95 \% \mathrm{CI}=1.859-10.454\right)$. Also, GT 
TABLE 6: Association analysis between ADD1 rs4961-polymorphism and arterial hypertension development among individuals of different sexes.

\begin{tabular}{lccccc}
\hline Model of inheritance $^{1}$ & $P_{c}$ & $\mathrm{OR}_{\mathrm{c}}(95 \% \mathrm{CI})$ & $P_{\mathrm{c}}^{\text {int }}$ & $P_{a}$ & $\mathrm{OR}_{\mathrm{a}}(95 \% \mathrm{CI})$ \\
\hline \multirow{2}{*}{ Dominant } & 0.559 & $0.658(0.161-2.684)$ & \multirow{2}{*}{0.125} & 0.295 & $0.446(0.098-2.023)$ \\
\hline \multirow{2}{*}{ Overdominant } & 0.061 & $2.476(0.961-6.383)$ & & 0.045 & $2.787(1.022-7.6)$ \\
\hline \multirow{2}{*}{ Additive $^{2}$} & 0.734 & $0.779(0.185-3.281)$ & \multirow{2}{*}{0.269} & 0.402 & $0.513(0.108-2.437)$ \\
& 0.137 & $2.062(0.794-5.355)$ & & 0.105 & 0.049 \\
\hline
\end{tabular}

$P_{c}:$ crude $P$ value; $\mathrm{OR}_{c}$ : crude odds ratio; $\mathrm{P}_{\mathrm{c}}^{\text {int }}:$ crude $P$ value interaction terms; $P_{a}: P$ value adjusted for age, $\mathrm{BMI}$, and smoking habit; $\mathrm{OR}_{\mathrm{a}}$ odds ratio adjusted for age, BMI, and smoking habit; $\mathrm{P}_{\mathrm{a}}^{\text {int }}: P$ value interaction terms adjusted for covariates; $95 \%$ CI: $95 \%$ confidence interval. 1: upper row: results for males; lower row: results for females. 2: upper row: comparison between GT and TT genotypes; lower row: comparison between TT and GG genotypes.

TABLE 7: Analysis of the association between ADD1 rs4961-polymorphism and arterial hypertension occurrence according to BMI.

\begin{tabular}{|c|c|c|c|c|c|c|}
\hline Model of inheritance ${ }^{1}$ & $P_{c}$ & $\mathrm{OR}_{\mathrm{c}}(95 \% \mathrm{CI})$ & $P_{\mathrm{c}}^{\text {int }}$ & $P_{a}^{3}$ & $\mathrm{OR}_{\mathrm{a}}(95 \% \mathrm{CI})$ & $P_{\mathrm{a}}^{\text {int3 }}$ \\
\hline \multirow{2}{*}{ Dominant } & 0.556 & $0.682(0.191-2.433)$ & \multirow{2}{*}{0.017} & $0.407(0.39)$ & $0.564(0.145-2.186)$ & \multirow{2}{*}{$0.027(0.077)$} \\
\hline & 0.001 & $4.408(1.859-10.454)$ & & $0.006(0.063)$ & $3.527(1.442-8.625)$ & \\
\hline \multirow{2}{*}{ Overdominant } & 0.556 & $0.682(0.191-2.433)$ & \multirow{2}{*}{0.025} & $0.405(0.387)$ & $0.561(0.144-2.185)$ & \multirow{2}{*}{$0.032(0.092)$} \\
\hline & 0.002 & $4.07(1.649-10.046)$ & & $0.001(0.094)$ & $3.418(1.342-8.704)$ & \\
\hline \multirow{2}{*}{ Additive $^{2}$} & 0.556 & $0.682(0.191-2.433)$ & \multirow{2}{*}{0.021} & $0.407(0.392)$ & $0.564(0.145-2.187)$ & \multirow{2}{*}{$0.028(0.079)$} \\
\hline & 0.002 & $4.312(1.74-10.689)$ & & $0.008(0.072)$ & $3.582(1.402-9.154)$ & \\
\hline
\end{tabular}

$P_{c}$ : crude $P$ value; $\mathrm{OR}_{c}$ crude odds ratio; $P_{\mathrm{c}}^{\text {int }}$ crude $P$ value interaction terms; $P_{a} P$ value adjusted for age and smoking habit; $\mathrm{OR}_{\mathrm{a}}$ odds ratio adjusted for age and smoking habit; $\mathrm{P}_{\mathrm{a}}{ }^{\text {int }} P$ value interaction terms adjusted for covariates; $95 \%$ CI $95 \%$ confidence interval. 1upper rowresults for BMI $<25 \mathrm{~kg} / \mathrm{m}^{2}$; lower rowfor $\mathrm{BMI} \geq 25 \mathrm{~kg} / \mathrm{m}^{2}$. 2: upper row: comparison between GT and TT genotypes; lower row: comparison between TT and GG genotypes. $3 P$ value adjusted for sex is shown in parentheses.

genotype has a significantly higher $\mathrm{AH}$ development risk than GG genotype under overdominant $\left(\mathrm{OR}_{\mathrm{c}}=4.07 ; 95 \%\right.$ $\left.\mathrm{CI}=1.649-10.046 ; \mathrm{P}_{\mathrm{c}}=0.002\right)$ and additive $\left(\mathrm{OR}_{\mathrm{c}}=4.312 ; 95\right.$ $\left.\% \mathrm{CI}=1.74-10.689 ; \mathrm{P}_{\mathrm{c}}=0.002\right)$ models. After adjusting for covariates (age and smoking habit), a significant association remained under each model of inheritance $\left(\mathrm{OR}_{\mathrm{a}}=3.527 ; 95\right.$ $\% \mathrm{CI}=1.442-8.625 ; \mathrm{P}_{\mathrm{a}}=0.006$ for the dominant model; $\mathrm{OR}_{\mathrm{a}}=3.418 ; 95 \% \mathrm{CI}=1.342-8.704 ; \mathrm{P}_{\mathrm{a}}=0.001$ for the overdominant model; $\mathrm{OR}_{\mathrm{a}}=3.582 ; 95 \% \mathrm{CI}=1.402-9.154$; $\mathrm{P}_{\mathrm{a}}=0.008$ for additive model). It should be noted that BMI is a risk modifier for $\mathrm{AH}$ development both before $\left(P_{\mathrm{c}}{ }^{\text {int }}=0.017 ; P_{\mathrm{c}}{ }^{\text {int }}=0.025 ; P_{\mathrm{c}}{ }^{\text {int }}=0.021\right.$, respectively $)$ and after adjustment for covariates $\left(P_{\mathrm{a}}{ }^{\text {int }}=0.027 ; P_{\mathrm{a}}{ }^{\text {int }}=0.032\right.$; $P_{\mathrm{a}}$ int $=0.028$, respectively). However, there was no significant association after adjusting for sex under all models of inheritance $\left(\mathrm{P}_{\mathrm{a}}>0.05\right.$ та $\left.P_{\mathrm{a}}^{\text {int }}>0.05\right)$.

The assessment of salt-sensitive $\mathrm{AH}$ development risk depending on the ADD1 Gly460Trp genotype is shown in Table 8 . The minor T allele $(\mathrm{GT}+\mathrm{TT})$ carriers were found to have a higher salt-sensitive $\mathrm{AH}$ development risk than $\mathrm{G}$ allele $(G G)$ carriers $\left(P_{c}=0.013\right)$ under the dominant model of inheritance $\left(\mathrm{OR}_{\mathrm{c}}=3.201 ; 95 \% \mathrm{CI}=1.285-7.977\right)$. Also, GT genotype has a significantly higher salt-sensitivity development risk than GG genotype under overdominant $\left(\mathrm{OR}_{\mathrm{c}}=2.557 ; 95 \% \mathrm{CI}=1.013-6.455 ; \mathrm{P}_{\mathrm{c}}=0.047\right)$ and additive $\left(\mathrm{OR}_{\mathrm{c}}=2.774 ; 95 \% \quad \mathrm{CI}=1.083-6.952 ; \quad \mathrm{P}_{\mathrm{c}}=0.033\right)$ models. After adjusting for covariates (age, smoking habit, $\mathrm{AH}$ grade, and $\mathrm{AH}$ presence in the family history), a significant association remained under dominant $\left(\mathrm{OR}_{\mathrm{a}}=3.141\right.$; $\left.95 \% \mathrm{CI}=1.221-8.08 ; \mathrm{P}_{\mathrm{a}}=0.018\right)$ and additive $\left(\mathrm{OR}_{\mathrm{a}}=2.756\right.$; $\left.95 \% \mathrm{CI}=1.056-7.196 ; \mathrm{P}_{\mathrm{a}}=0.038\right)$ models. After adjusting for sex and BMI, a significant association was lost under all models of inheritance $\left(\mathrm{P}_{\mathrm{a}}>0.05\right)$.

The next analysis stage was to study the distribution of genotypes and alleles in $\mathrm{AH}$ patients of different sexes and salt-sensitivity development risk assessment. The distribution of ADD1 Gly460Trp-polymorphic variants is presented in Table 9. The GG, GT, and TT genotype distribution in the salt-sensitive female group was 25 (54.4\%), 18 (39.1\%), and $3(6.5 \%)$, while that in the salt-resistant female group was 23 $(82.1 \%), 5(17.9 \%)$, and $0(0 \%)$, respectively. There were statistically significant differences in both genotype $(P=0.04)$ and allele $(P=0.011)$ distributions in these comparison groups. In males, significant differences in genotype and allele distributions were not revealed $(P>0.05)$.

Binary logistic regression analysis showed that the presence of minor T allele (GT- and TT genotype) has a higher risk of salt-sensitivity development in females than $\mathrm{GG}$ genotype $\left(\mathrm{OR}_{\mathrm{c}}=3.864 ; 95 \% \mathrm{CI}=1.251-11.935\right.$; $\left.\mathrm{P}_{\mathrm{c}}=0.019\right)$. Also, the GT genotype has a significantly higher salt-sensitivity development risk than GG genotype under additive model $\left(\mathrm{OR}_{\mathrm{c}}=3.312 ; 95 \%\right.$ $\left.\mathrm{CI}=1.058-10.369 ; \mathrm{P}_{\mathrm{c}}=0.04\right)$. After adjusting for covariates (age, smoking habit, $\mathrm{AH}$ grade, and $\mathrm{AH}$ presence in the family history), a statistically significant link remained under dominant $\left(\mathrm{OR}_{\mathrm{a}}=5.213 ; 95 \% \mathrm{CI}=1.36-19.99\right.$; $\left.\mathrm{P}_{\mathrm{a}}=0.016\right)$ and additive $\left(\mathrm{OR}_{\mathrm{a}}=4.445 ; \quad 95 \quad \%\right.$ $\left.\mathrm{CI}=1.151-17.165 ; \mathrm{P}_{\mathrm{a}}=0.03\right)$ models of inheritance $(\mathrm{Ta}-$ ble 10). However, there was no significant association after adjusting for BMI under all models of inheritance $\left(\mathrm{P}_{\mathrm{a}}>0.05\right)$. 
TABLE 8: Association analysis between ADD1 rs4961-polymorphism and salt-sensitivity occurrence.

\begin{tabular}{lcccc}
\hline Model of inheritance & $P_{c}$ & $\mathrm{OR}_{\mathrm{c}}(95 \% \mathrm{CI})$ & $P_{a}{ }^{2}$ & $\mathrm{OR}_{\mathrm{a}}(95 \% \mathrm{CI})$ \\
\hline Dominant & 0.013 & $3.201(1.285-7.977)$ & $0.018(0.443)$ & $3.141(1.221-8.08)$ \\
Overdominant $^{1}$ & 0.047 & $2.557(1.013-6.455)$ & $0.054(0.574)$ & $2.562(0.983-6.675)$ \\
Additive $^{1}$ & 0.033 & $2.774(1.083-6.952)$ & $0.038(0.509)$ & $2.756(1.056-7.196)$ \\
\hline
\end{tabular}

$P_{c}$ crude $P$ value; $\mathrm{OR}_{c}$ crude odds ratio; $P_{a} P$ value adjusted for age, smoking habit, $\mathrm{AH}$ presence in family history, and $\mathrm{AH}$ grade; $\mathrm{OR}_{\mathrm{a}}$ odds ratio adjusted for age, smoking habit, AH presence in family history, and AH grade; 95\% CI95\% confidence interval. 1upper row: comparison between GT and TT genotypes; lower row: comparison between TT and GG genotypes. 2: $P$ value adjusted for sex and BMI is shown in parentheses.

TABle 9: Distribution of the ADD1 rs4961-polymorphism alleles and genotypes among males and females.

\begin{tabular}{|c|c|c|c|c|}
\hline & \multicolumn{2}{|c|}{ SS } & \multicolumn{2}{|c|}{ SR } \\
\hline & $\mathrm{n}$ & $\%$ & $\mathrm{n}$ & $\%$ \\
\hline & \multicolumn{4}{|c|}{ Males $(n=46)$} \\
\hline & \multicolumn{4}{|c|}{ Genotypes } \\
\hline GG & 16 & 100 & 27 & 90 \\
\hline GT & 0 & 0 & 3 & 10 \\
\hline TT & 0 & 0 & 0 & 0 \\
\hline \multirow[t]{2}{*}{$\mathrm{P}$} & \multicolumn{4}{|c|}{0.191} \\
\hline & \multicolumn{4}{|c|}{ Alleles } \\
\hline G & 32 & 100 & 57 & 95 \\
\hline $\mathrm{T}$ & 0 & 0 & 3 & 5 \\
\hline \multirow[t]{3}{*}{$\mathrm{P}$} & \multicolumn{4}{|c|}{0.198} \\
\hline & \multirow{2}{*}{\multicolumn{4}{|c|}{$\begin{array}{c}\text { Females }(n=74) \\
\text { Genotypes }\end{array}$}} \\
\hline & & & & \\
\hline GG & 25 & 54.4 & 23 & 82.1 \\
\hline GT & 18 & 39.1 & 5 & 17.9 \\
\hline TT & 3 & 6.5 & 0 & 0 \\
\hline \multirow[t]{2}{*}{$\mathrm{P}$} & \multirow{2}{*}{\multicolumn{4}{|c|}{$\begin{array}{l}0.04 \\
\text { Alleles }\end{array}$}} \\
\hline & & & & \\
\hline G & 68 & 73.9 & 51 & 91.1 \\
\hline $\mathrm{T}$ & 24 & 26.1 & 5 & 8.9 \\
\hline $\mathrm{P}$ & \multicolumn{4}{|c|}{0.011} \\
\hline
\end{tabular}

$n$ : number of cases; SS: salt-sensitive; SR: salt-resistant.

\section{Discussion}

Adducin is a heterodimeric protein of the cell cytoskeleton that consists of 3 subunits $(\alpha, \beta, \gamma)$. Alpha- and gammaadducins are presented in almost all tissues, whereas betaadducin is highly expressed in brain tissues and located in the erythrocyte membrane as a cytoplasmic protein. Adducin has various important types in physiological processes. Alpha-adducin is a major membrane ion transport regulator. It promotes spectrin to actin attachment, is able to bind to calmodulin, a substrate for protein kinases $\mathrm{C}$ and $\mathrm{A}$, and regulates the $\mathrm{Na}^{+}-\mathrm{K}^{+}$-ATPase activity (transports sodium and potassium ions through the renal epithelium membrane). The structural feature of alpha- and betaadducins is the presence of protease-resistant N-terminal region and protease-sensitive hydrophilic C-terminal region in their molecules $[15,28]$.

The various protein subunits are encoded by different genes ( $A D D 1, A D D 2$, and $A D D 3)$ on three different chromosomes. Alternative splicing determines the existence of different adducin isoforms; however, not all variants have been fully described for today. The adducin $\alpha$-subunit gene $(A D D 1)$ (NCBI) is located at the short arm of the 4 th chromosome in the 16.3 segment. It consists of 16 exons (from 34 to $1892 \mathrm{bp}$ ) [29, 30].

Gly460Trp-polymorphism (rs4961) is the most studied and functionally important $A D D 1$ gene polymorphic site. The essence of rs4961-polymorphism is the replacement of guanine by thymine at the 1378th position in ADD1 mRNA (NM_001119.4). In turn, it leads to the replacement of glycine by tryptophan in the 460th position of the polypeptide chain [24].

Cusi et al. for the first time established the association between ADD1 Gly460Trp-polymorphism and AH development for the French and Italians [10]. In 1998, consistent data were obtained by S. Tamaki et al. for the Japanese. Later, Nakamura et al. conducted a large-scale study involving an abundant amount of patients to study 4 genetic $\mathrm{AH}$ predictors. The authors concluded that ADD1 Gly460Trppolymorphism is an independent genetic marker for $\mathrm{AH}$ occurrence in the Japanese population [12]. An association between $\mathrm{T}$ allele and $\mathrm{AH}$ development was revealed among Russians [15], Chinese [14], Japanese [11], inhabitants of Madeira [18], Tunisia [16], North Africa [13], and Asian population [17]. The results we have obtained also indicate an association between ADD1 Gly460Trp-polymorphism and $\mathrm{AH}$ occurrence in Ukrainians and demonstrate the higher $\mathrm{T}$ allele frequency in patients with salt-sensitive $\mathrm{AH}$. However, it should be noted that after adjusting for covariates, a statistically significant link remained only in the female subgroup. The minor Tallele carriers were revealed to have a higher $\mathrm{AH}$ development risk.

Howsoever, the association between ADD1 Gly460Trppolymorphism and $\mathrm{AH}$ occurrence was not found in patients with essential AH, namely, the inhabitants of India [22], Korea [21], Japan [19], and America [20].

Investigating the possible $A D D 1$ role as an $\mathrm{AH}$ genetic marker has practical importance. Cusi et al. [10] in their first works have already shown a higher $\mathrm{T}$ allele frequency in patients with salt-sensitive AH. They also described the association between this polymorphism and high blood pressure and its decrease after salt intake reducing. In 2002, Psaty et al. [31] and, later, Citterio et al. [32] described that T allele patients (GT and TT genotypes) differ in a significant blood pressure decrease after hydrochlorothiazide diuretics application. We have obtained comparable results regarding the protective minor $\mathrm{T}$ allele value in the salt-resistant $\mathrm{AH}$ development. However, it should be noted that sex and BMI are also important factors that determine the sensitivity to salt intake reducing in patients with high blood pressure.

The adducin gene regulates blood pressure, mainly by affecting the $\mathrm{Na}^{+}-\mathrm{K}^{+}$-ATPase activity and altering the 
TABLE 10: Association analysis between ADD1 rs4961-polymorphism and salt-sensitivity occurrence among females.

\begin{tabular}{lcccr}
\hline Model of inheritance & $\mathrm{P}_{\mathrm{c}}$ & $\mathrm{OR}_{\mathrm{c}}(95 \% \mathrm{CI})$ & $P_{a}{ }^{2}$ & $\mathrm{OR}_{\mathrm{a}}(95 \% \mathrm{CI})$ \\
\hline Dominant & 0.019 & $3.864(1.251-11.935)$ & $0.016(0.258)$ & $5.213(1.36-19.99)$ \\
Overdominant & 0.061 & $2.957(0.951-9.191)$ & $0.053(0.377)$ & $3.714(0.983-14.03)$ \\
Additive $^{1}$ & 0.04 & $3.312(1.058-10.369)$ & $0.03(0.3)$ & $4.445(1.151-17.165)$ \\
\hline
\end{tabular}

$P_{c}$ crude $P$ value; $\mathrm{OR}_{c}$ crude odds ratio; $P_{a} P$ value adjusted for age, smoking habit, $\mathrm{AH}$ presence in family history, and AH grade; $\mathrm{OR}_{\mathrm{a}}$ odds ratio adjusted for age, smoking habit, AH presence in family history, and AH grade; 95\% CI95\% confidence interval. 1upper row: comparison between GT and TT genotypes; lower row: comparison between TT and GG genotypes. 2: $P$ value adjusted for BMI is shown in parentheses.

sodium reabsorption by the renal tubules [30]. In vivo adducin is a substrate for PKC, PKA, and Rho-associated kinase [28] and is involved in cell signal transduction. Besides, adducin interacts with other membrane skeleton components and membrane proteins to influence ion transport, particularly, $\mathrm{Na}^{+}$transport $\left(\mathrm{Na}^{+}\right.$channels, $\mathrm{Na}^{+}-$ $\mathrm{H}^{+}$exchange, $\mathrm{Na}^{+}-\mathrm{Li}^{+}$countertransport, and $\mathrm{Na}^{+}-\mathrm{K}^{+}-\mathrm{Cl}^{-}$ cotransport) [33,34]. $\alpha$ - or $\beta$-adducin point mutations can lead to hypertension, as the phosphorylation pattern changes from tyrosine kinase to the PKA site. The mutated $\alpha$-adducin variants have been shown to interact with the Src-SH2 domain, increasing Src activity and phosphorylation and activity of Src-dependent $\mathrm{Na}^{+}-\mathrm{K}^{+}$- ATPase [35].

Several studies have approved the blood pressure normalization in hypertensive rats under the rostafuroxin influence (antihypertensive drug) that suppressed the $\alpha$-adducin and Src-SH2 domain interaction and disrupted the $\mathrm{Src}$ activation and $\mathrm{Na}^{+}-\mathrm{K}^{+}$-ATPase phosphorylation [36]. The association between ADD1 Gly460Trp-polymorphism and the response to rostafuroxin treatment has been shown in clinical studies of the Chiara Lanzani group [37].

There is a high scientific community interest in the $A D D 1$ participation in AH occurrence. Several meta-analyses have been recently performed to study the association between hypertension risk and genetic polymorphisms. In 2010, Liu et al. [8] and Ramu et al. [22] reported on the lack of association between the $\alpha$-adducin Gly460Trp-polymorphism and AH. At the same time, Liao et al. [23] and Jin et al. [24] support the hypothesis that $\mathrm{T}$ allele carriers have a higher AH developing risk in Asian populations. The results' ambiguity can be explained by several reasons. First is the $\mathrm{AH}$ heterogeneity and its ethnic characteristics. A large number of the studies demonstrated a link between Gly460Trp-polymorphic variants and $\mathrm{AH}$ for the Asian population, while data for other populations differ. Secondly, hypertension is a multifactorial disease, and most studies do not consider environmental factors (geographical location, climate, diet, and lifestyle) that are also associated with hypertension risk. In addition, one of the potential limitations may be small sample sizes and the inability to include all current research into meta-analyses.

On the one hand, $A D D 1$ is an important $\mathrm{AH}$ gene candidate, and on the other hand, the obtained data are controversial. Our results show that gender is an important modifier of the rs4961 ADD1 genotype effect on AH development. A previous study established the insignificant sex by genotype interaction for rs4961 in an investigated white population. However, researchers have found that Gly460Trp polymorphism in interaction with C1797T polymorphism of $A D D 2$ increases the risk of hypertension in all women (adjusted relative risk, $\mathrm{RR}=2.35, P=0.01$ ) and postmenopausal subjects ( $R R=2.92, P=0.03)$, but not in men. Moreover, women with T alleles in both rs4961 and C1797 loci had a significantly higher plasma renin activity relative to CC carriers, whereas the opposite effect was observed in men. Thus, the authors hypothesized that the sexual differences in rs4961 influence on AH development may be associated with the renin-angiotensin-aldosterone system [38].

Another potential mechanism to explain such observations is the existence of gender dimorphism in the $\mathrm{CpG}$ methylation pattern distribution along the $A D D 1$ promoter region. It was found for the Chinese population that $A D D 1$ CPG methylation level was associated with essential hypertension (EH) with a significantly higher methylation degree in females than in males. Further analysis showed that a lower methylation level of CpG1 dinucleotide was linked to increased EH risk among females, but not males. In contrast, the lower degree of CpG2-5 methylation was associated with higher EH risk exclusively among males [39]. The comparable results were received in recent research for Egyptians. The authors hypothesized that a lower level of $A D D 1 \mathrm{CpG}$ methylation causes a higher expression of $\alpha$-adducin and $\mathrm{Na}^{+}-\mathrm{K}^{+}$-ATPase which leads to more intense $\mathrm{Na}^{+}$reabsorption and EH development, consequently [40]. Thus, further studies are needed to confirm these hypotheses.

It is worth noting that the study has some limitations. The comparison groups should be expanded to confirm the results. It should be noted that the adjustment for only three variables (age, BMI, and smoking) was used in regression analysis. Moreover, along with the Gly460Trp-polymorphic locus influence on the $\mathrm{AH}$ development, the importance of other, nongenetic, factors (sex, BMI, etc.) has been established. It is further important to determine the $A D D 1$ gene expression level, depending on its polymorphic variant, which is necessary for the Gly460Trp-polymorphism functional value establishing. Due to the existence of gender dimorphism, it will be necessary to estimate the interaction effect of rs4961 and C1797 SNP on AH development as well as investigate the methylation level of $\mathrm{CpG}$ islands in the $A D D 1$ promoter region.

\section{Conclusions}

Thus, ADD1 Gly460Trp-polymorphism was found to increase the $\mathrm{AH}$ risk and the salt-sensitive $\mathrm{AH}$ development among the Ukrainian population. Further studies are 
necessary to confirm the obtained results and to establish the other nongenetic factors' role in the $\mathrm{AH}$ development, depending on the Gly460Trp-polymorphism genotype.

\section{Data Availability}

The data used to support the findings of this study are available from the corresponding author upon request.

\section{Conflicts of Interest}

The authors declare that there are no conflicts of interest.

\section{References}

[1] K. T. Mills, A. Stefanescu, and J. He, "The global epidemiology of hypertension," Nature Reviews Nephrology, vol. 16, no. 4, pp. 223-237, 2020.

[2] E. M. Degoma, G. Rivera, S. M. Lilly, M. H. U. Usman, and E. R. Mohler, "Personalized vascular medicine: individualizing drug therapy," Vascular Medicine, vol. 16, no. 5, pp. 391-404, 2011.

[3] A. V. Ataman, V. Y Garbusova, Y. A Ataman, O. I. Matlaj, and O. A. Obuchova, "Investigation of the MGP promoter and exon 4 polymorphisms in patients with ischemic stroke in the Ukrainian population," Journal of Cell and Molecular Biology, vol. 10, no. 1, pp. 19-26, 2012.

[4] Y. I. Dubovyk, V. Yu. Harbuzova, and A. V. Ataman, "G1639A but Not C1173T VKORC1 gene polymorphism is related to ischemic stroke and its various risk factors in Ukrainian population," BioMed Research International, vol. 2016, Article ID 1298198, 2016.

[5] H. R. Warren, E. Evangelou, and C. P. Cabrera, "Genomewide association analysis identifies novel blood pressure loci and offers biological insights into cardiovascular risk," Nature Genetics, vol. 49, no. 3, pp. 403-415, 2017.

[6] I. A. Dudchenko, L. N. Pristupa, L. N. Pristupa, and A. V. Ataman, "Genetic dependency of blood pressure and heart rate in patients with arterial hypertension and obesity," Annals of the Russian Academy of Medical Sciences, vol. 69, no. 5-6, pp. 40-46, 2014.

[7] J. A. Staessen, J.-G. Wang, E. Brand et al., "Effects of three candidate genes on prevalence and incidence of hypertension in a Caucasian population," Journal of Hypertension, vol. 19, no. 8, pp. 1349-1358, 2001.

[8] K. Liu, J. Liu, and Y. Huang, "Alpha-adducin Gly460Trp polymorphism and hypertension risk: a meta-analysis of 22 studies including 14303 cases and 15961 controls," PLoS One, vol. 5, no. 9, Article ID e13057, 2010.

[9] J. R. Zhang, W. N. Hu, and C. Y. Li, "A review of the epidemiological evidence for adducin family gene polymorphisms and hypertension," Cardiology Research and Practice, vol. 2019, Article ID 7135604, 2019.

[10] D. Cusi, C. Barlassina, T. Azzani et al., "Polymorphisms of $\alpha$-adducin and salt sensitivity in patients with essential hypertension," The Lancet, vol. 349, no. 9062, pp. 1353-1357, 1997.

[11] S. Tamaki, N. Iwai, Y. Tsujita, Y. Nakamura, and M. Kinoshita, "Polymorphism of .ALPHA.-Adducin in Japanese patients with essential hypertension," Hypertension Research, vol. 21, no. 1, pp. 29-32, 1998.

[12] Y. Nakamura, Y. Tabara, T. Miki et al., "Both angiotensinogen $\mathrm{M} 235 \mathrm{~T}$ and $\alpha$-adducin G460W polymorphisms are associated with hypertension in the Japanese population," Journal of Human Hypertension, vol. 21, no. 3, pp. 253-255, 2007.

[13] C. Barlassina, G. R. Norton, and N. J. Samani, "Alpha-adducin polymorphism in hypertensives of South African ancestry," American Journal of Hypertension, vol. 13, no. 1, pp. 719-723, 2000.

[14] Z. Ju, H. Zhang, and K. Sun, "Alpha-adducin gene polymorphism is associated with essential hypertension in Chinese," Journal of Hypertension, vol. 21, no. 10, pp. 1861-1868, 2003.

[15] A. V. Polonikov, D. V. Ushachev, and A. M. Shestakov, "Polymorphism Gly460Trp of alpha-adducin gene and predisposition to essential hypertension. The role of gene-environment interactions in the development of the disease in Russian population," Kardiologiia, vol. 51, no. 10, pp. 33-39, 2011.

[16] H. Soualmia, A. Ben Romdhane, and F. Midani, "Alpha adducin G460T variant is a risk factor for hypertension in tunisian population," Clinical Laboratory, vol. 62, no. 5, pp. 765-770, 2016.

[17] Y.-L. Qu, C.-M. Wu, and L.-X. Zhang, “Association between alpha-adducin gene rs4963 polymorphism and hypertension risk in Asian population: a meta-analysis," Cellular and Molecular Biology, vol. 62, no. 13, pp. 62-64, 2016.

[18] A. C. Sousa, R. Palma Dos Reis, and A. Pereira, "Relationship between ADD1 Gly460Trp gene polymorphism and essential hypertension in Madeira Island," Medicine (Baltimore), vol. 96, no. 42, p. e7861, 2017.

[19] K. Ishikawa, T. Katsuya, and N. Sato, "No association between $\alpha$-adducin 460 polymorphism and essential hypertension in a Japanese population," American Journal of Hypertension, vol. 11, no. 4, pp. 502-506, 1998.

[20] N. Larson, R. Hutchinson, and E. Boerwinkle, "Lack of association of 3 functional gene variants with hypertension in African Americans," Hypertension, vol. 35, no. 6, pp. 1297-1300, 2000.

[21] M.-H. Shin, E.-K. Chung, and H.-N. Kim, "Alpha-adducin Gly460Trp polymorphism and essential hypertension in Korea," Journal of Korean Medical Science, vol. 19, no. 6, pp. 812-814, 2004.

[22] P. Ramu, G. Umamaheswaran, and D. G. Shewade, "Gly460Trp polymorphism of the ADD1 gene and essential hypertension in an Indian population: a meta-analysis on hypertension risk," Indian Journal of Human Genetics, vol. 16, no. 1, pp. 8-15, 2010.

[23] X. Liao, W. Wang, and Z. Zeng, "Association of alpha-ADD1 gene and hypertension risk: a meta-analysis," Medical Science Monitor: International Medical Journal of Experimental and Clinical Research, vol. 21, pp. 1634-1641, 2015.

[24] H. Jin, Y. Huang, and G. Yang, "Association between $\alpha$-adducin rs4961 polymorphism and hypertension: a metaanalysis based on 40432 subjects," Journal of Cellular Biochemistry, vol. 120, no. 3, pp. 4613-4619, 2019.

[25] World Health Organization-International Society of Hypertension Guidelines for the Management of Hypertension, "Guidelines subcommittee," Journal of Hypertension, vol. 17, no. 2, pp. 151-183, 1999.

[26] G. Mancia, G. De Backer, and A. Dominiczak, "Guidelines for the management of arterial hypertension: the task force for the management of arterial hypertension of the European society of hypertension (ESH) and of the European society of Cardiology (ESC)," European Heart Journal, vol. 28, no. 12, pp. 1462-1536, 2007. 
[27] F. Elijovich, M. H. Weinberger, C. A. M. Anderson et al., "Salt sensitivity of blood pressure," Hypertension, vol. 68, no. 3, pp. e7-e46, 2016.

[28] Y. Matsuoka, X. Li, and V. Bennett, "Adducin is an in vivo substrate for protein kinase C: phosphorylation in the MARCKS-related domain inhibits activity in promoting spectrin-actin complexes and occurs in many cells, including dendritic spines of neurons," Journal of Cell Biology, vol. 142, no. 2, pp. 485-497, 1998.

[29] B. Lin, J. Nasir, H. McDonald et al., "Genomic organization of the human $\alpha$-adducin gene and its alternately spliced isoforms," Genomics, vol. 25, no. 1, pp. 93-99, 1995.

[30] G. Bianchi, G. Tripodi, G. Casari et al., "Two point mutations within the adducin genes are involved in blood pressure variation," Proceedings of the National Academy of Sciences, vol. 91, no. 9, pp. 3999-4003, 1994.

[31] B. M. Psaty, N. L. Smith, and S. R. Heckbert, "Diuretic therapy, the $\alpha$-adducin gene variant, and the risk of myocardial infarction or stroke in persons with treated hypertension," JAMA, vol. 287, no. 13, pp. 1680-1689, 2002.

[32] L. Citterio, C. Lanzani, and P. Manunta, "Polymorphisms, hypertension and thiazide diuretics," Pharmacogenomics, vol. 12, no. 11, pp. 1587-1604, 2011.

[33] B. K. Berdiev, A. G. Prat, H. F. Cantiello et al., "Regulation of epithelial sodium channels by short actin filaments," Journal of Biological Chemistry, vol. 271, no. 30, pp. 17704-17710, 1996.

[34] P. A. Mead, J. N. Harvey, P. A. Rutherford, H. Leitch, and T. H. Thomas, "Sodium-lithium countertransport and the Gly460 $\longrightarrow$ Trp $\alpha$-adducin polymorphism in essential hypertension," Clinical Science, vol. 108, no. 3, pp. 231-236, 2005.

[35] S. Tisminetzky, G. Devescovi, and G. Tripodi, "Genomic organisation and chromosomal localisation of the gene encoding human beta adducing," Gene, vol. 167, no. 1-2, pp. 313-316, 1995.

[36] C. F. Wenceslau and L. V. Rossoni, "Rostafuroxin ameliorates endothelial dysfunction and oxidative stress in resistance arteries from deoxycorticosterone acetate-salt hypertensive rats," Journal of Hypertension, vol. 32, no. 3, pp. 542-554, 2014.

[37] C. Lanzani, L. Citterio, and N. Glorioso, "Adducin- and ouabain-related gene variants predict the antihypertensive activity of rostafuroxin, part 2: clinical studies," Science Translational Medicine, vol. 2, no. 59, Article ID 59ra87, 2010.

[38] J.-G. Wang, J. A. Staessen, C. Barlassina et al., "Association between hypertension and variation in the $\alpha$ - and $\beta$-adducin genes in a white population," Kidney International, vol. 62, no. 6, pp. 2152-2159, 2002.

[39] L. N. Zhang and P. P. Liu, "Lower ADD1 gene promoter DNA methylation increases the risk of essential hypertension"” PLoS One, vol. 15, no. 8, Article ID e63455, 2013.

[40] N. M. K. Bayoumy, M. M. El-Shabrawi, and O. F. Leheta, " $\alpha$-Adducin gene promoter DNA methylation and the risk of essential hypertension," Clinical and Experimental Hypertension, vol. 39, no. 8, pp. 764-768, 2017. 